\title{
La protección jurídica a las personas en situación de vulnerabilidad y el respeto a la autonomía de la voluntad*
} Lituations and respect for voluntary autonomy

\author{
Enrique Jorge Arévalo**
}

\section{RESUMEN}

El presente trabajo intenta discurrir sobre una noción de vulnerabilidad que trascienda su vinculación con las situaciones de debilidad individual o colectiva sin excluirlas. Propugna una concepción totalizadora del concepto, recordando que todo ser humano es esencialmente vulnerable. Aborda la inveterada exclusión de los sujetos más vulnerables y su lucha pertinaz en pos de su inserción social. Analiza la tutela que el derecho penal argentino ofrece a esas personas a través del análisis de una sentencia que trata la figura de circunvención de incapaces. Particular atención se dispensa a la figura del notario en cuanto a la valoración a su cargo, respecto del discernimiento de los otorgantes y la función preventiva que cumple el autorizante.

PALABRAS CLAVE: Vulnerabilidad, discriminación, igualdad, inclusión social, discernimiento.

\begin{abstract}
This work intends to reflect on the concept of vulnerability that transcends its connection with the situation of individual weakness or even collective weakness, without exclusion. It advocates a holistic understanding of the concept, remembering that every human being is essentially vulnerable. It tackles the longstanding exclusion of the most vulnerable subjects and the prolonged struggle in pursuit of their social inclusion. It also analyses the protection that Argentine criminal law offers to these people through the analysis of a judgement that presents the situation of circumvention for incapable persons. Particular attention is given to the position of the notary in respect of the value of his office, with regard to the discernment of licensors and the preventive role that comes with this authorization.
\end{abstract}

KEY WORDS: Vulnerability, discrimination, equality, social inclusion, discernment.

\footnotetext{
* Recibido: 4 de mayo de 2015. Aceptado: 8 de junio de 2015.

** Notario en la Dirección del Archivo de Protocolos Notariales del Colegio de Escribanos de la Provincia de Santa Fe -2da. Circunscripción. República Argentina (martacaporossi@hotmail.com.)
} 


\section{SUMARIO}

1. Algunas ideas introductorias

2. Antecedentes normativos: la larga lucha por la inserción social

3. La tutela penal: el delito de circunvención de incapaces en la jurisprudencia

4. El notario y el discernimiento de los otorgantes. La función preventiva del asesoramiento

5. La tutela de los derechos de las personas en situación de vulnerabilidad

6. Conclusiones

\section{Algunas ideas introductorias}

\subsection{Sobre la noción de vulnerabilidad}

El diccionario refiere que la expresión vulnerable se aplica "a la persona, al carácter o al organismo que es débil o que puede ser dañado o afectado fácilmente porque no sabe o no puede defenderse: los niños son vulnerables; tiene un carácter vulnerable; está bajo de defensas y es muy vulnerable a las infecciones". También indica respecto de vulnerable "que puede ser herido o recibir lesión física o moralmente”. ${ }^{1}$ El concepto refiere, básicamente, a la aptitud individual psicofísica propia de cada sujeto para prevenir o repeler adecuadamente los efectos de las enfermedades o agresiones físico-morales. Otros detallan los diversos campos y acepciones que pueden asignarse al término; lo definen, por ejemplo, como el grado de preparación de las comunidades o gobiernos para enfrentar desastres naturales; también se aplica a lo inherente a la personalidad de cada individuo (comportamientos ante situaciones extremas), a la informática (violación de confidencialidad del sistema), etcétera. Se trata de ideas parciales.

La Federación Internacional de Sociedades de la Cruz Roja y de la Media Luna Roja sostiene: "la vulnerabilidad puede definirse como la capacidad disminuida de una persona o un grupo de personas para anticiparse, hacer frente y resistir a los efectos de un peligro natural o causado por la actividad humana y para recuperarse de los mismos”. Se trata de una mirada que intenta abarcar tanto el punto de vista individual como el social; indica una variante más amplia de causas (naturales o humanas) generadoras. El informe vincula a la vulnerabilidad esencialmente con la pobreza. ${ }^{2}$

\footnotetext{
' Real Academia Española. Diccionario de la Lengua Española, Madrid, 1992.

${ }^{2}$ Informe de la Federación Internacional de la Cruz Roja y de la Media Luna (organización humanitaria mundial con 189 sociedades miembros).
} 
El criterio expuesto anteriormente, más onmicomprensivo que el anterior, puede ampliarse, a su vez, señalando que la situación de vulnerabilidad trasciende la carencia de recursos materiales, a pesar de ser uno de sus factores desencadenantes. Entendemos que la raíz de ese estado de indefensión se encuentra en la situación de marginalidad que soportan personas o grupos de personas que se ven privadas a diario de prestaciones esenciales (salud, educación, seguridad), deberes irrenunciables a cargo del Estado (como afirman los artículos 14 bis, 75 inciso 18, Constitución Nacional, tratados y leyes "dictadas en su consecuencia"). Desde ese punto de vista, el flagelo de la marginación no limita su nefasto accionar a las personas indigentes, sino que impacta sobre diversos núcleos sociales (étnicos, religiosos, políticos), si bien la gravedad que alcanzan sus efectos suele ser diversa.

Igualmente, corresponde considerar a la ignorancia como una usina generadora de vulnerabilidad, fundamentalmente porque impide a cada ser humano adquirir plena consciencia de sus propias limitaciones. Esa desventaja (falta de conocimientos) induce a los sujetos a la toma de decisiones perjudiciales para ellos y su entorno social. ${ }^{3}$

La vulnerabilidad, examinada en su mayor amplitud, es un fenómeno estrechamente vinculado con la muerte; como tal, se exterioriza en infinidad de formas y tiempos, pero golpea de modo implacable a la totalidad de los individuos y estratos sociales. En otras palabras: la vulnerabilidad es la antesala de la muerte y, tarde o temprano, con mayor o menor sufrimiento y permanencia, nos alcanza a todos. Desde esa óptica, se puede afirmar que todos los seres humanos somos vulnerables. Es el estado en que encuentran los seres vivientes, a despecho de la relativa protección que garantizan las organizaciones forjadas por las distintas civilizaciones. ${ }^{4} \mathrm{Si}$ además consideramos que la supervivencia de cada uno, particularmente en las etapas de la infancia y vejez (y en ocasiones soportar cualquier dolencia -transitoria o permanente-), depende en gran medida de los cuidados de otros, debe concluirse que todo ser humano es esencialmente vulnerable.

Sin perder de vista esa concepción totalizadora de la vulnerabilidad, centraremos nuestra atención en el examen de algunos principios jurídicos que tutelan los derechos de aquellas personas que a causa de alguna discapacidad, de carácter transitorio o permanente, o por encontrarse atravesando el estado

\footnotetext{
${ }^{3}$ Como claramente lo expresa Gerardo Pascualini, "la ignorancia, cuando se la reconoce es útil; lo malo es cuando no se sabe que no se sabe". Pascualinı, Gerardo. "Ética: la palabra devaluada", en José, Burucúa, La Ética del Compromiso, GEA, Buenos Aires, 2003, p. 131.

4 "El hombre es fundamentalmente vulnerable y la muerte puede entrar por todos los rincones del edificio corporal". Jankélévich, Vladimir. Pensar la Muerte, Fondo de Cultura Económica, Buenos Aires, 2004, p. 24.
} 
de vejez o minoridad, padecen cotidianamente sus efectos. Abordamos pues, una de las facetas que integran ese amplio espectro abarcado por el término vulnerabilidad.

\subsection{La inveterada exclusión de los sujetos más vulnerables}

Tradicionalmente, el trato para con las personas afectadas por discapacidad mental (capacidades diferentes) se desenvolvió en el marco de un régimen legal que, en su versión más benigna, alentaba su exclusión social. Pero en determinadas épocas y lugares, ese rechazo alcanzó extremos macabros: se propugnaba la eliminación lisa y llana de tales sujetos.

Un antecedente remoto pero representativo del grado que puede alcanzar la sevicia humana se encuentra en la antigua Esparta, donde se sacrificaba a todo recién nacido considerado inepto para el servicio del Estado. Se trata de actos repudiables de acuerdo con los valores morales vigentes, pero debe recordarse que se llevaron a la práctica dentro de un contexto histórico determinado: la Antigüedad.

En cambio, resulta ominoso para todo el género humano que, en pleno siglo xx, amparándose en los principios de una "nueva ciencia", cuyo objetivo era el mejoramiento de las aptitudes de la raza humana, se consumara el exterminio de personas que, supuestamente, no respondían a los estándares de excelencia. Se verificó un verdadero retroceso en la moral colectiva de algunas naciones, impropio para la altura de los tiempos. ${ }^{5}$

Pero, como señalamos al principio, prevaleció el rechazo social hacia las personas con capacidades diferentes, aun más profundo en el caso de los sujetos mentalmente minusválidos. Esa idiosincrasia alcanzó, en la modernidad, un profundo arraigo, particularmente entre las clases altas y media, y determinó el ocultamiento ante el medio social de familiares discapacitados. Esta actitud se complementó con la sustitución total de su voluntad. Acertadamente, se rotuló la situación de los discapacitados psíquicos como "escondidos de la sociedad". ${ }^{6}$

\footnotetext{
${ }^{5}$ La "nueva ciencia" a que nos referimos es la eugenesia, designada en esa forma por Sir Francis Galton (1822-1911), quien desarrolló los primeros conceptos ante la Royal Society de Londres. Entre sus cultores, se encuentran el italiano Nicola Pende (1880-1970), considerado el artífice de la eugenesia en la Italia fascista (véase "Futuro", suplemento de ciencias del diario Página 12, año 26, No. 125, 15 de septiembre, 2014). El concepto "la altura de los tiempos" lo desarrolla José Ortega y Gasset en su ya clásica obra: Ortega y GaSset, José. La Rebelión de las Masas, Planeta De Agostini, Barcelona, 1993, p. 56.

${ }^{6}$ Benigno Varela Autrán atribuye esa caracterización a la Secretaria General de Amnistía Internacional, en ocasión de celebrarse el Día Mundial de la Salud Mental. Véase Varela Autrán, Benigno. "La protección jurídica de las personas con discapacidad intelectual límite: curatela, guarda de hecho y otras figuras", Seminario organizado por el Consejo General del Notariado Español en la UIMP, julio-agosto, 2007, p. 76.
} 
Se gestó así un régimen absolutamente segregacionista, legitimado normativamente mediante el diseño y puesta en marcha de sistemas que garantizaran su exclusión social. No resulta casual que "los procedimientos de exclusión de los locos han mostrado y liberado, a partir del siglo XIX y una vez más sobre la base de ciertas transformaciones, un beneficio político y también eventualmente una cierta utilidad económica que han solidificado el sistema y lo han hecho funcionar en su conjunto". Abundan los ejemplos sobre maniobras dolosas de sujetos moralmente abominables, tendientes a obtener la declaración de incapacidad de algún familiar con fines de aprovechamiento económico.

Las circunstancias señaladas resultaron determinantes en el tratamiento discriminatorio que soportaron los sujetos afectados por capacidades diferentes. Ellos forman parte de la extensa nómina de personas integrantes de grupos raciales, religiosos, sociales, políticos, laborales que resultan víctimas de un marcado menoscabo en sus derechos. Aún hoy, en la segunda década del siglo xxI, deviene indispensable la planificación y puesta en marcha de una política de Estado que haga efectivos los derechos reconocidos a las personas con capacidades diferentes, entre ellas las que conforman las personas con necesidades educativas especiales. Entre otras decisiones, resulta imprescindible la cobertura por parte de las obras sociales estatales y privadas.

Los procedimientos discriminatorios alcanzan su variante más extrema en los actos de violencia, tanto de índole física como moral, que soportan muchos sujetos en condiciones de mayor vulnerabilidad, particularmente los ancianos. ${ }^{8}$ No debe olvidarse la institución de internados en siniestros lugares designados como manicomios, en los cuales el paciente sufría toda clase de degradaciones físico-morales, incluyendo (en épocas más recientes) el macabro comercio de sus propios órganos con fines de trasplante..$^{9}$ La codicia resultó ser un notable estimulante de la inventiva humana en su variante más perversa.

Ese criterio, sintéticamente expuesto, encontró recepción legislativa en el artículo 475 de nuestro viejo Código Civil, que extendió la aplicación de las

\footnotetext{
${ }_{7}^{7}$ Foucault, Michel. Microfísica del Poder, Edymión, Madrid, 1992, p. 149.

${ }^{8}$ A título de ejemplo, Ana Isabel Berrocal Lanzarot recuerda: "como una realidad más, que afecta a este colectivo de personas mayores [...] se constata un aumento de situaciones de maltrato a ancianos de carácter doméstico, en el seno de la propia familia, habitualmente por un miembro de la misma". BerRoCAL LANZAROt, Ana IsABel. "La protección jurídica de los mayores en situación de desamparo: ¿Extensión de la guarda y tutela pública a estos supuestos?", en La defensa jurídica de las personas vulnerables, Seminario organizado por el Consejo Federal del Notariado en la UIMP, julio-agosto, 2007, España, Aranzadi, 2008, p. 127.

${ }^{9}$ Caló, Emanuele. Bioética. Nuevos derechos y autonomía de la voluntad, La Rocca, Avellaneda, Buenos Aires, 2000, pp. 153-154. "Enigmas de la Crónica Policial. El Misterio de la Colonia Psquiátrica", en Diario La Capital de Rosario. El informe revela macabros casos de mutilación de pacientes internados con fines de comercialización de órganos con fines de trasplante.
} 
"leyes sobre la tutela de menores [...] a la curadoría de los incapaces". El principio general quedó plasmado en el artículo 377, que definía tutela como "el derecho que confiere la ley para gobernar la persona y bienes del menor de edad que no está sujeto a la patria potestad", y en el 411, que otorga al tutor amplios poderes de representación, facultándolo a ejecutar todos los actos en nombre del pupilo "prescindiendo de su voluntad".

En el régimen impuesto originariamente por el Código Civil, en su artículo 264, la patria potestad fue concebida como "el conjunto de los derechos que las leyes conceden a los padres desde la concepción de los hijos legítimos, en las personas y bienes de dichos hijos, mientras sean menores de edad". Ese concepto autoritario se extiende, en los artículos 327 y 328, a los hijos naturales. El vínculo paterno-filial preservaba, fundamentalmente, la autoridad e intereses de los progenitores. De acuerdo con el esquema resumido, los deseos de los representados que reúnen las características indicadas (menores sujetos a patria potestad o tutela o aquellos que se encuentran bajo el régimen de curatela) resultan absolutamente ignorados. ${ }^{10}$

La doctrina justificó esa posición excluyente relativa a la capacidad de hecho sosteniendo que "la capacidad es una institución que funciona a través de tipos rígidos que introducen una gran seguridad en las relaciones jurídicas, no obstante que en algún supuesto pueda traer aparejado un resultado injusto: es el fin no querido por la ley de que hablara Ihering”. ${ }^{11}$ En consecuencia, la incapacitación de hecho absoluta implicaba colocar al demente declarado o al menor de edad en una situación de inhabilidad que le cercenaba toda posibilidad de ser parte en cualquier relación jurídica. ${ }^{12}$ Las restricciones impuestas a toda gestión personal por parte del incapaz abarcaban, conforme lo sostenía la doctrina que aquí recordamos, contenidos patrimoniales y personales. Este último aspecto alcanzaba hasta los actos personalísimos. ${ }^{13}$

Corresponde señalar que esa generación de tratadistas (Orgaz, por ejemplo), a pesar de que aprobaba el sistema representativo vigente, lo consideraba excesivo en cuanto a los efectos sustitutivos de la voluntad del representado que abarcaban a los incapaces relativos dotados de discernimiento. Ya se reconocía la variante de la "asistencia" y se le conceptuaba como "una adición de voluntades”. La resultante era un acto complejo compuesto por la voluntad del interesado (incapaz) y la conformidad del órgano tutelar (padre, tutor, juez).

\footnotetext{
${ }^{10}$ Llambias, Jorge Joaduin. Tratado de Derecho Civil, tomo I, Perrot, Buenos Aires, p. 39.

"Crovi, Luis Daniel. "Capacidad Jurídica de las Personas con Padecimientos Mentales", en La Ley, No. 203, 25 de octubre, 2011, p. 1.

12 Salvat, Raymundo. Tratado de Derecho Civil Argentino, Parte General, p. 605.

${ }^{13}$ Ibidem, p. 620.
} 
La asistencia, prevista originariamente para casos de matrimonios de menores de edad, actos de menores emancipados, obtuvo reconocimiento por medio de la reforma operada mediante la ley nacional 17711, que contempló en el artículo 152 bis los supuestos de inhabilitación judicial. ${ }^{14}$

\section{Antecedentes normativos: la larga lucha por la inserción social}

El largo camino recorrido en procura del efectivo reconocimiento como sujetos de derecho a todos aquellos que padecen en forma transitoria o permanente los efectos de la situación de vulnerabilidad, encuentra, en nuestro país, un punto de partida en la consagración constitucional de los principios de igualdad (artículos 14 y, específicamente, 16 de nuestra Constitución Nacional). Pero esa proclamada igualdad -de carácter formal-se limita a los derechos al trabajo, comercio, petición, libertad ambulatoria, asociación; a "los empleos sin otra condición que la idoneidad", y al cumplimiento de obligaciones impositivas.

En relación con los derechos políticos, se prohibió al pueblo el ejercicio directo de todo acto de gobierno (artículo 22 de la Constitución Nacional). Fue la resultante del pensamiento burgués que tuvo su origen en el siglo xvII y alcanzó pleno desarrollo en la siguiente centuria: el poder "emanaba" del pueblo pero de ningún modo podía ejercerlo por sí mismo; esa atribución correspondía a sus representantes. ${ }^{15}$ Como la elección de los representantes se concretó en nuestro medio durante décadas mediante procedimientos fraudulentos, esa desigualdad participativa generó encarnizadas luchas que culminaron en el reconocimiento del "derecho-deber" al sufragio universal (al principio, y durante mucho tiempo, exclusivamente masculino), mediante la sanción de ley nacional 8871, conocida como Ley Saenz Peña, de 1912.

La ineficacia de los postulados constitucionales originarios (de neto corte económico-liberal) frente a las abismales desigualdades económico-sociales estimuló iniciativas parlamentarias tendientes a paliar esa grave situación.

\footnotetext{
${ }^{14}$ Lo novedoso de ese instituto fue el rol asignado al curador: la necesaria conformidad de éste a los fines de la celebración de los actos relativos a la disposición de bienes entre vivos y la posibilidad de que los inhabilitados otorguen "por sí solos actos de administración, salvo los que limite la sentencia de inhabilitación, teniendo en cuenta las circunstancias del caso". Conforme surge del mandato legal, quien realiza los actos jurídicos es el propio inhabilitado, pero se encuentra sujeto al contralor del curador, quien cumple funciones de asistencia. El criterio aquí sintetizado recibió reconocimiento jurisprudencial. cNA Civil, Sala L, 30 de mayo, 2000, citado por Código Civil de la República Argentina, Legis, Argentina, 2007, p. 83.

${ }^{15}$ El principio consagratorio de la soberanía en cabeza del pueblo se utilizó en la lucha que mantuvo la burguesía europea contra el absolutismo monárquico. Fue una herramienta que resultó idónea para obtener el apoyo de la plebe, pero en modo alguno se pensó en otorgarle a ésta poder de decisión. Un análisis de esa cuestión puede verse en Guérin, Daniel. La lucha de clases en el apogeo de la Revolución francesa, R y R, Buenos Aires, 2011.
} 
Así, a principios del siglo xx, se sancionan las primeras leyes protectoras del trabajo, como la que establece el descanso dominical (número 4661, año 1905) y la reglamentaria del trabajo de mujeres y menores (número 5291, año 1907).

Transcurrieron varias décadas para que en nuestra Carta Magna (1956) alcanzara el mayor rango normativo la protección a los derechos individuales y colectivos del trabajo y de la seguridad social (artículo 14 bis), sin olvidar el antecedente plasmado en la reforma operada en el año 1949, derogada en 1955. La modificación de 1956 recogió los principios proclamados por el constitucionalismo social, respuesta doctrinaria-legislativa a las ingentes demandas sociales posteriores a la Primera Guerra Mundial. Las primeras concreciones se observan en la Constitución mexicana de 1917, la soviética y la alemana, ambas de 1919.

La largamente anhelada igualdad real de oportunidades obtiene su espaldarazo constitucional en Argentina a través de la reforma de 1994 que la incluye en el artículo 75, inciso 23. ${ }^{16}$ Asimismo, en las naciones iberoamericanas, se advierte -en épocas recientes- un sostenido movimiento constitucional consagratorio de la protección de los discapacitados. ${ }^{17}$ La tremenda devastación humana ocasionada por la Segunda Guerra Mundial generó, por parte de organismos internacionales (la onU y la OEA, entre otros), un conjunto de declaraciones, tratados, convenciones, leyes y pactos garantistas en materia de derechos humanos que integran nuestro derecho positivo.

Debemos reconocer como un valioso antecedente de tales instrumentos a la célebre Declaración de los Derechos del Hombre y del Ciudadano, emanada de la Asamblea Constituyente el 04 de agosto de 1789, todavía reunida en Versalles, que "en menos de doce horas" puso fin a un régimen que había sobrevivido por mil años: la monarquía francesa. ${ }^{18}$

En una incompleta tarea exegética, seleccionamos preceptos de ese conjunto normativo que consideramos herramientas conducentes a la efectiva protección de los sujetos en situación de mayor vulnerabilidad que, aún en plena centuria posmoderna, sufren las consecuencias de la desigualdad de hecho. La amplitud que actualmente corresponde asignar a la actual formulación jurídica de los derechos humanos, que tutela a las personas contra las violaciones más aberrantes (tortura, genocidio, persecuciones políticas) y a las que sufren el cercenamiento de sus personalísimos (identidad, privacidad, salud, autodeterminación, dignidad), ameritan suficientemente el emprendimiento de esta modesta tarea. ${ }^{19}$

\footnotetext{
${ }^{16}$ Davove-Barbero. Op. cit., p. 36.

17 Pérez Galardo, Leonardo. "La protección social de los discapacitados en Cuba: una visión de lege data y de lege ferenda", en Revista del Instituto de Derecho e Integración, No. 3, año 2, p. 149.

${ }^{18}$ Caló Emanuele. Op. cit., p. 50.

${ }^{19}$ Madeln, Louis. Los Hombres de la Revolución Francesa, La Asamblea Constituyente, Javier Vergara, Buenos Aires,
} 
2.1 Declaración Americana de los Derechos y Deberes del Hombre, IX Conferencia Internacional Americana. Bogotá, 1948

Artículo 2. Derecho de Igualdad ante la Ley: Consagrado para todas las personas "sin distinción de raza, sexo, idioma, credo ni otra alguna". Artículo 16. Establece para toda persona el derecho a la seguridad social "que le proteja contra las consecuencias de la desocupación, vejez e incapacidad".

Artículo 29. Deber de convivencia de toda persona "de manera que todas y cada una puedan formar y desenvolver íntegramente su personalidad".

Artículo 30. Refiere al deber de asistencia por parte de cada persona a sus hijos menores de edad.

2.2 Declaración Universal de los Derechos Humanos. Resolución 217 A. Asamblea General de las Naciones Unidas (1948)

Artículo 1. Igualdad. Dignidad y derechos a todos los seres humanos. Artículo 2. Los derechos proclamados por la Declaración se garantizan a toda persona, "sin distinción alguna de raza, color, sexo, idioma, religión o de cualquier otra índole”.

La declaración apuntada dispone en forma recurrente y sistemática (artículos $1,2,4,7,10,16,25)$ el tratamiento al derecho de igualdad de las personas, sin diferenciación alguna. A pesar de la meridiana claridad de lo expuesto en instrumentos como el resumido, el persistente estado de discriminación continuó afectando a la mujer durante todo el siglo xx.

Esa anacrónica y vejatoria situación fundamentó el dictado de la Convención sobre Eliminación de todas las Formas de Discriminación contra la Mujer por parte de la Asamblea General de la Naciones Unidas, el 17 de julio de 1980. El artículo 16 encomienda a los Estados la adopción de "todas las medidas adecuadas para eliminar la discriminación contra la mujer". Expresamente, reivindica el derecho por parte de la mujer a la elección del apellido (inciso g).

La República Argentina ratificó esa Convención por ley 23179, que fuera incorporada a la Constitución Nacional en la reforma realizada en 1994 (artículo 75, inciso 22). Esa norma se encuentra incluida entre los tratados y 
concordatos con "jerarquía superior a las leyes”. En lo que refiere al apellido de la mujer casada en la República Argentina, se mantuvo la inveterada y vetusta normativa consistente en la agregación a su prenombre de origen el que correspondía a su marido, precedido de la preposición "de" hasta alcanzar las postrimerías del siglo xx. La ley 23515, sancionada el 3 de junio de 1987, reconoce a la mujer casada, con carácter optativo, el derecho de agregar a su apellido el de su marido, precedido de la preposición "de". ${ }^{20}$

2.3 Convención Americana sobre Derechos Humanos (Pacto de San José de Costa Rica, 1969. Ley 23054, 1984)

Artículo 1. Los Estados parte asumen el compromiso de respetar los derechos y libertades reconocidos por la propia convención y "a garantizar su libre ejercicio a toda persona que esté sujeta a su jurisdicción, sin discriminación alguna por motivos de raza, color, sexo o de cualquier otra índole".

Artículo 19. Derecho del niño "a las medidas de protección que su condición de menor requieren por parte de su familia, de la sociedad y del Estado".

\subsection{Pacto Internacional de Derechos Civiles y Politicos,} ratificado por Ley 23313 (1986)

Artículo 26. Consagra el principio de igualdad de todas las personas ante la ley y su derecho sin discriminación a igual protección ante la ley. Establece que la ley "prohibirá toda discriminación y garantizará a todas las personas protección igual y efectiva contra cualquier discriminación por motivos de raza, color, sexo, idioma, religión [...] nacimiento o cualquier otra condición social."

\subsection{Convención sobre los Derechos del Niño.}

Ley 23849/1990

El preámbulo recuerda que las Naciones Unidas, en su Declaración Universal de los Derechos Humanos, "proclamaron que la infancia tiene derechos a cuidados especiales”. Desarrolla principios relativos a la igualdad, garantías

\footnotetext{
${ }^{20}$ La preposición "de" refiere posesión o pertenencia. Es un resabio subsistente a pesar de su anacronismo ontológico, de la consideración de la mujer como objeto.
} 
contra toda forma de discriminación, derecho a la vida, supervivencia, desarrollo, identidad y su preservación (inscripción, nacimiento, nacionalidad, conocimiento, progenitores), integración con núcleo familiar (padres), atención por los Estados de solicitudes de ingreso o salidas de Estados parte, derecho a expresar opinión en asuntos que lo afecten, y a ser escuchado en todo procedimiento judicial o administrativo que lo afecte, libertad de expresión y búsqueda de información, libertad de pensamiento, conciencia y religión, libertad de asociación y reunión, protección ante injerencias arbitrarias de la vida privada, acceso a la información, obligaciones comunes de ambos padres en la crianza y educación; protección contra toda forma de perjuicio o abuso físico o mental, descuido, malos tratos, interés superior del niño en los sistemas de adopción (autorizada por autoridades competentes, medio de cuidar al niño, salvaguardas en niños adoptados en otro país, evitar beneficios financieros indebidos por participantes), protección y asistencia para niño refugiado, disfrute de la vida plena y decente al niño mental o físicamente impedido (cuidados especiales, asistencia gratuita, integración social), derecho a la salud, atención sanitaria prenatal y postnatal, atención sanitaria preventiva; derecho a nivel de vida adecuado, derecho a educación (enseñanza primaria obligatoria y gratuita, desarrollo enseñanza secundaria), desarrollo de la personalidad.

\subsection{Convención Interamericana para la Eliminación de todas las Formas de Discriminación contra las Personas con Discapacidad. Guatemala, 1999}

Aprobada por Ley Nacional 25280 (во 4 de agosto, 2000), puntualiza como objetivos de la Convención, en su artículo 2, "la prevención y eliminación de todas las formas de discriminación contra las personas con discapacidad y propiciar su plena integración a la sociedad".

En el artículo 1 caracteriza a la discapacidad como "deficiencia física, mental o sensorial [...] permanente o temporal, que limita la capacidad de ejercer una o más actividades esenciales de la vida diaria”. El precepto designa como discriminación a "toda distinción, exclusión o restricción basada en una discapacidad, antecedente de discapacidad, consecuencia de discapacidad [...] que tenga el efecto o propósito de impedir o anular el reconocimiento, goce o ejercicio de las personas con discapacidad de sus derechos humanos y libertades fundamentales". Aclara que "no constituye discriminación la distinción o preferencia adoptada por un Estado parte a fin de promover la integración social o el desarrollo personal de las personas con discapacidad". 
2.7 Convención sobre los Derechos de las Personas con Discapacidad. Naciones Unidas, 2006, aprobada por Ley Nacional 26378

En el punto $p$ del preámbulo, se destaca la preocupación de los Estados parte "por la difícil situación en que se encuentran las personas con discapacidad que son víctimas de múltiples o agravadas formas de discriminación”. En el artículo 1, se vuelca como propósito de la Convención "promover, proteger y asegurar el goce pleno y en condiciones de igualdad de todos los derechos humanos y libertades fundamentales por todas las personas con discapacidad".

Entre los principios generales de la Convención, en el artículo 3, se mencionan: la no discriminación, la igualdad de oportunidades, la accesibilidad, la igualdad entre el hombre y la mujer (incisos $b, e, f, g$ ). Las obligaciones generales que asumen los Estados parte incluyen la toma de medidas que modifiquen disposiciones legales, costumbres y prácticas "que constituyan discriminación contra las personas con discapacidad" (inciso b) y para que "ninguna persona, organización o empresa privada discrimine por motivos de discapacidad” (inciso e).

El artículo 5 ratifica el principio de igualdad ante la ley para todas las personas, el compromiso de los Estados parte relativo a la prohibición de toda discriminación por motivos de discapacidad, garantizando a los sujetos involucrados su protección legal y efectiva contra esa práctica (incisos 1 y 2). El inciso 4 del mismo artículo no considera discriminatorias a "las medidas específicas que sean necesarias para acelerar o lograr la igualdad de hecho de las personas con discapacidad".

\subsection{Significaciones atribuidas al término discriminación}

Puede advertirse que tanto la normativa extraída en el punto anterior como la sancionada por la Convención Interamericana para la Eliminación de todas las Formas de Discriminación para las Personas con Discapacidad, en sintonía con el sistema normativo vigente, adoptan el sentido disvalioso atribuido al término discriminación. Pero esa palabra contiene significados opuestos. Desde el punto de vista sociológico, se considera a la discriminación como "un fenómeno de poder, un reparto autoritario de sentidos".

No obstante que ambos preceptos analizados reservan esa designación para las acciones excluyentes, debe recordarse que todo acto de gobierno que favorezca a determinados sujetos, tendiente a garantizar su inclusión social y al ejercicio efectivo del derecho de igualdad, también constituye discriminación 
(designada como discriminación inversa, incluyente o acción afirmativa) pero que, en este supuesto, merece valoración positiva. ${ }^{21}$

\subsection{Ley 23592. Penalización de actos discriminatorios}

Penaliza a "Quien arbitrariamente impida, obstruya, restrinja de algún modo menoscabe el pleno ejercicio sobre bases igualitarias de los derechos y garantías fundamentales, reconocidos por la Constitución Nacional”. Entre los actos y omisiones considerados como discriminatorios, se indican: "raza, religión, nacionalidad, ideología [...] o caracteres físicos".

Una de las acepciones que corresponde a la palabra caracteres es "el conjunto de cualidades o circunstancias propias [...] de una persona”. El precepto legal, en su actual redacción, permite accionar al damnificado que presente capacidades mentales diferentes en tanto exteriorice determinados caracteres físicos. La determinación de la conducta antijurídica -en este caso la discriminación- encuentra su origen exclusivamente en la ley, sancionada teniendo en cuenta valores imperantes en el medio social. ${ }^{22}$

El proyecto de modificación de esta normativa, ingresado el 19 de mayo del 2010 al Congreso de la Nación, ampliaba el espectro de actos "u omisiones discriminatorios" al incluir a la discapacidad dentro de los supuestos contemplados. La posterior sanción de la Ley Nacional 26657, el 25 de noviembre del 2010 y promulgada el 02 de diciembre del mismo año (Derecho de Protección de la Salud Mental), incluye en los actos discriminatorios -artículo 28-, en los términos de la ley 23592, a cualquier negativa por parte de los centros hospitalarios a la atención de pacientes "por el solo hecho de tratarse de problemática de salud mental".

La doctrina refiere que la responsabilidad civil emergente de los actos discriminatorios se extiende al ámbito contractual y extracontractual, incluso precontractual, presupone un actuar arbitrario y, en determinadas circunstancias, es la consecuencia del ejercicio abusivo del derecho. ${ }^{23}$ Por ende, contiene los elementos comunes que caracterizan a los referidos regímenes de responsabilidad: antijuricidad, daño, relación de causalidad entre daño y hecho y factores de imputabilidad o atribución legal de responsabilidad. ${ }^{24}$

\footnotetext{
${ }^{21}$ Davove-Barbero. Op. cit., p. 13.

${ }^{22}$ El principio general se encuentra regulado por el artículo 1066 del Código.

${ }^{23}$ KIPER, Claudio. "Discriminación y Responsabilidad Civil", en Revista de Responsabilidad Civil y Seguros, vol. 3, 2011. En el artículo 1071 del Código Civil se contemplan casos frecuentes en el ejercicio abusivo del derecho. Resultan frecuentes con motivo de la aplicación por parte de propietarios de establecimientos públicos del cuestionado derecho de admisión.

${ }^{24}$ Bustamante Alsina, Jorge. Teoría general de la responsabilidad civil, Abeledo Perrot, Buenos Aires, 1993, p. 106.
} 
La antijuricidad de las conductas discriminatorias encuadra en el delito civil (artículo 1072 del Código Civil) si se comprueba que el acto ilícito ha sido "ejecutado a sabiendas y con intención de dañar", es decir, con dolo. Igualmente, se extiende a las situaciones culposas por cuanto se sancionan las actuaciones arbitrarias (artículo 1, ley 23592). Debe tenerse en cuenta que a los fines de la reparación resulta suficiente la comprobación del daño sufrido por la víctima, independientemente de la reprobación que merezca la conducta del autor, en la medida en que el accionar de este último genere el resultado disvalioso. Resulta innecesaria la existencia de una norma expresa que prohíba ciertas conductas con miras a la existencia de una ilicitud objetiva. ${ }^{25}$

La armonización de lo normado por el artículo 1 de la ley 23592 con los principios obrantes en la Convención Interamericana para la Eliminación de todas las formas de Discriminación contra las Personas con Discapacidad (Guatemala, 8 de junio, 1999), aprobada por ley nacional 25280 (во 04 de agosto, 2000), permite solucionar el problema de la laguna legislativa indicada al principio, en virtud del criterio interpretativo establecido en el artículo 16 del Código Civil. ${ }^{26}$

\subsection{Convención Internacional de los Derechos del Niño y Ley Nacional 26061}

Estos instrumentos normativos han sido caracterizados como un verdadero hito en la historia de los derechos de la infancia; se erigen como el máximo exponente de la doctrina de la protección integral de los derechos del niño. ${ }^{27}$

El enunciado de su artículo 1 (objeto) resulta suficientemente clarificador: "la protección integral de las niñas, niños y adolescentes". Descarta posibles controversias sobre la naturaleza de los derechos y garantías que designa como de "orden público, irrenunciables, interdependientes, indivisibles e intransigibles” (artículo 2). Se tutela especialmente su condición de sujetos de derecho y

\footnotetext{
${ }^{25}$ KIPER, Op. cit., p. 12; C. Nac. A. Sala D, 29-02-1996- "T.C. c/ Municipalidad de Bs. As); C. A. C. y C. Mar del Plata, Sala II, 16-12-2003. Ambos fallos citados en "Código Civil de la República Argentina", Legis, 2007, notas al artículo 1066. La Cámara Nacional Civil Sala D en fecha 12 de noviembre, 2008, autos "Jhoslen, Eduardo Julián c/Transporte DUVI SA", resolvió que la empresa prestataria del servicio de transporte debía responder por los daños y perjuicios padecidos por una persona a quien se le negó el expendio del boleto gratuito, contrariando la resolución dictada por la Secretaría de Transporte.

${ }^{26}$ Este precepto indica que para la resolución de vacios normativos puede acudirse "a los principios de leyes análogas" y, supletoriamente, a "los principios generales del derecho". La jurisprudencia ha sostenido que "es regla en la interpretación de las leyes dar pleno efecto a la intención del legislador, computando la totalidad de sus preceptos de manera que armonicen con el orden jurídico restante y con los principios y garantías de la Constitución Nacional". Corte Suprema de Justicia de la Nación. Dulcamara vs Entel, 23 de marzo, 1990.

${ }^{27}$ RaumiL, Alcia Beatriz y Arévalo, E. Jorge. "Capacidad jurídica de los menores de edad y autonomía progresiva en el ejercicio de sus derechos", en Revista del Instituto de Derecho e Integración, No. 3, año 2, Colegio de Escribanos de la Provincia de Santa Fe, p. 90.
} 
el respeto a sus opiniones -que deben ser objeto de atención-, principios que se desarrollan extensivamente en la totalidad del precepto (artículo 3).

El título II (Principios, derechos y garantías) reconoce el primigenio derecho a la vida (el artículo 9 comprende el disfrute, la protección y obtención de buena calidad de vida), a la vida privada e intimidad (el artículo 10 debe relacionarse con el 16 de la Convención Internacional de los Derechos del Niño), derecho a la identidad (según el artículo 11, incluye derecho al nombre, nacionalidad, lengua de origen, conocimiento filiatorio, cultura de origen, preservación de identidad), derecho a la identificación (artículo 12; individualización de recién nacidos en forma gratuita, obligatoria, oportuna). Este derecho se vincula con el que garantiza la obtención de la documentación que acredite la identidad de los sujetos (artículo 13). El derecho a la salud, mediante la asistencia integral, rehabilitación e integración, está previsto en el artículo 14, y su aplicación se encuentra a cargo de los organismos estatales.

Particular atención corresponde brindar al artículo 15, garante del derecho a la educación pública, gratuita y obligatoria, atendiendo a los objetivos de un desarrollo integral del sujeto, su preparación para el ejercicio de la ciudadanía, formación para la convivencia democrática y el ejercicio del derecho al trabajo (artículo 14 bis de la Constitución Nacional). El artículo 16 ratifica la garantía de la gratuidad de la educación "en todos los servicios estatales, niveles y regímenes especiales de conformidad con lo estatuido en el ordenamiento jurídico vigente". ${ }^{28}$

El precepto antes glosado guarda estrecha relación con uno de los puntos que desarrollan el concepto de interés superior en el artículo 3. Se trata del equilibrio necesario entre los derechos y garantías consagrados y "las exigencias del bien común" (inciso e). La adecuada formación de los integrantes de un sistema republicano requiere, ineludiblemente, la enseñanza de sus deberes hacia la comunidad de la cual forman parte.

La prohibición de actos discriminatorios es tratada en dos artículos. El 17 otorga esa protección por "estado de embarazo, maternidad y paternidad" ante eventuales tentativas sancionatorias por parte de instituciones. Por su parte, el artículo 28 ordena la aplicación de las disposiciones consagradas "sin discriminación fundada en motivos raciales, color, edad, idioma, capacidades especiales". El sistema legislativo vigente faculta al niño para ejercer, ante cualquier acto discriminatorio que lo afecte, las acciones previstas en la ley 23592, analizada en el punto anterior.

\footnotetext{
${ }^{28}$ La importancia de la educación en el régimen republicano fue destacada por filósofos y políticos en forma inveterada. La menciona Montesquieu en El Espiritu de las Leyes (libro 3, capitulo v). Para este autor, la educación es una condición previa e indispensable para la existencia de la virtud, cualidad inherente al sistema republicano.
} 
El derecho de los niños de expresar libremente su opinión en asuntos que les conciernan y sean de su interés, cuyas opiniones deben "ser tenidas en cuenta, conforme su grado de madurez y desarrollo" (artículo 24), se complementa con el de ser oído por la autoridad competente y que su opinión sea tomada en cuenta en decisiones que lo afecten. ${ }^{29}$ Integra el sistema la posibilidad de contar con asistencia letrada (artículo 27). A ello se suma que la ley 26061 fue dictada en cumplimiento de la obligación asumida por el Estado argentino dentro del marco de la Convención de los Derechos del Niño, aprobada por ley 23849 (во 22 de octubre, 1990), norma de "jerarquía superior a las leyes" (artículo 75, inciso 22, de la Constitución Nacional).

Garantizan la plena aplicación de los paradigmas estatuidos por la normativa aquí resumida, los preceptos desarrollados a partir del título III (artículos 32 y siguientes) designado como "Sistema de Protección Integral de los Derechos de las Niñas, Niños y Adolescentes”, que propenden al logro de los objetivos planteados por el legislador. ${ }^{30}$

\section{La tulela penal: el delito de circunvención de incapaces en la jurisprudencia}

A continuación brindaremos un resumen del fallo.

1. La figura legal de circunvención de incapaces (art. 174, inc. $2^{\circ}$ C.P.), supone abusar de las necesidades, pasiones o inexperiencia de un menor o de un incapaz, declarado o no tal, para hacerle firmar un documento que importe cualquier efecto jurídico, en daño de él o de otro, aún cuando el acto sea civilmente nulo. Se atiende a las menores posibilidades de defensa de quien por sus necesidades, pasiones o inexperiencia, facilita la defraudación. Es una defraudación por abuso de la condición de la víctima. [...]

\footnotetext{
${ }^{29}$ El derecho del niño a ser oído ha sido reconocido por la jurisprudencia con anterioridad a la sanción de la ley 26061. La Suprema Corte de la Provincia de Buenos Aires, en su Acordada 73814/2000, dijo: "Atento la trascendencia que a la decisión sobre el destino del menor se otorga se exige -bajo pena de nulidad- que quien vaya a resolver sobre él lo conozca". Citado por González, Maria Paula y Hernández, Natala. Participación de los niños y adolescentes en los procesos judiciales de familia, ponencia presentada en la Facultad de Derecho de la Universidad Nacional de Rosario, 2009.

${ }^{30}$ Julio A. Martínez Alcorta, en su monografía Responsabilidad de los equipos interdisciplinarios de salud mental, señala que un "paradigma comprende todas las producciones científicas de todas las disciplinas involucradas que son reconocidas universalmente como válidas en un determinado momento histórico. Estas producciones generan reglas y principios para la solución de problemas en una ciencia". El derecho tutela normativamente paradigmas sociales reconocidos en cada devenir histórico, respondiendo a las particularidades culturales de cada pais. Un pormenorizado análisis de la Ley Nacional 26061 puede encontrarse en el trabajo de Mirta Hebe Mangione Muro, Ley 26061 en Cuadros Sinópticos. Comentarios de la Ley.
} 
2. La figura requiere que el autor explote (abuse) los intereses (necesidades), afectos o apetitos (pasiones) del incapaz o su falta de saber o inadvertencia (inexperiencia). [...]

3. Es un delito de daño puramente eventual que se consuma con la firma del documento por el incapaz (insistimos: declarado o no como tal); es doloso y exige además el conocimiento de la incapacidad del otorgante, la intención de aprovecharse de su necesidad, pasión o inexperiencia. ${ }^{31}$

\subsection{Consideraciones}

El fallo dictado por el Tribunal Superior de Justicia de la Provincia de Córdoba el 28 de septiembre del 2012, bajo número 254, dentro de los autos "Murúa, María del Carmen PSA circunvención de incapaces, Recurso de Casación” (expediente M 24/12), constituye la aplicación concreta de principios legales relativos a la función tutelar que el derecho consagra en beneficio de las personas cuya vulnerabilidad adquiere caracteres críticos.

Ello no implica negar la sostenida evolución del instituto encaminada a la consagración de los derechos de las personas más desprotegidas, que contemplan el espectro que va desde la igualación de oportunidades, el respecto por la voluntad y la autonomía progresiva del sujeto (leyes nacionales 23849, $26378,26061,26657)$ a la que ya hemos aludido. En realidad, ambos aspectos están ligados indisolublemente entre sí: la protección y el ejercicio efectivo de los derechos de raigambre constitucional por parte de las personas en situación de vulnerabilidad.

\subsection{Sobre la figura penal}

El tipo penal se encuentra, como se dijo, regulado en el artículo 174, inciso 2, del Código Penal (conforme Ley Nacional 11221, de fe de erratas y vigente de acuerdo a la Ley 23077) y contempla la pena de prisión de 2 a 6 años para "El que abusare de las necesidades, pasiones o inexperiencia de un menor o de un incapaz, declarado o no declarado tal, para hacerle firmar un documento que importe cualquier efecto jurídico, en daño de él o de otro, aunque el acto sea civilmente nulo".

La doctrina sostiene que la existencia de la modalidad delictiva aquí reproducida no requiere necesariamente que el autor se sirva del engaño, sino que el hecho punible consiste en que aquellos abusen de la situación de

\footnotetext{
${ }^{31}$ La sentencia que analizamos fue integramente reproducida en la Revista del Instituto de Derecho e Integración, No. 9, año 5, p. 227.
} 
vulnerabilidad de la víctima, induciéndola a la suscripción de un documento portante de efectos jurídicos patrimoniales. ${ }^{32}$

La vulnerabilidad, considerada en puntos anteriores, la desarrolla el precepto a partir de tres ideas directrices: necesidades, pasiones o inexperiencia. Un abanico de acepciones refiere al significado de la voz necesidad. Así, puede tratarse de un impulso irresistible que determina el sentido de las decisiones, la carencia de cosas inherentes a la subsistencia, los padecimientos generados en riesgos o peligros que requieren inmediata asistencia; incluso, abarca aquellas privaciones de tipo espiritual y afectiva (índole religiosa, por ejemplo).

Adviértase que las necesidades contempladas por la norma no se ciñen en modo alguno a las de origen económico. La sentencia comparte el criterio expuesto por calificada doctrina en el sentido de que el abuso se extiende a las carencias de la víctima "de cualquier orden, siempre que sean producto de su padecimiento o edad y alcancen tal intensidad que disminuyan considerablemente su juicio crítico y las funciones volitiva y afectiva”. La sentencia admitió que las necesidades materiales de la víctima, en el caso examinado, no sufrieron menoscabo alguno como consecuencia del acto realizado (donación de nuda propiedad con reserva de usufructo vitalicio).

La pasión, vinculada con el delito analizado, puede contemplar casos de desequilibrios emocionales, marcadas inclinaciones personales o apetitos desmedidos de la víctima por alguna cosa, en tanto sea incapaz de dominarlos. La inexperiencia presupone insuficiencia de conocimientos, fundamentalmente de carácter práctico, en diversas cuestiones de la vida diaria.

La conjunción disyuntiva $o$ determina que a los fines de la concreción del tipo penal bastará alguna de las debilidades apuntadas: necesidades, pasiones o inexperiencia, complementado con las restantes circunstancias descritas en la norma. La punición de alguno de los hechos abusivos apuntados dependerá de la suscripción del documento por parte de alguno de los sujetos pasivos mencionados en el precepto: menor o incapaz, con independencia de su declaración como tal. El análisis del contenido del documento que otorgue la víctima servirá para develar la aptitud dañosa del acto en perjuicio del autor o de un tercero.

Atento a que el bien jurídico objeto de la tutela del legislador es el derecho de propiedad (título vi del Código Penal), el daño deberá ser de índole patrimonial, y será innecesario que el perjuicio se concrete. La peligrosidad del acto resulta suficiente para la consumación del delito. ${ }^{33}$ Por fin, debe señalarse que el hecho resulta punible con independencia de que el acto celebrado reúna las

\footnotetext{
32 Fontán Balestra, Carlos. Derecho penal, Abeledo Perrot, Buenos Aires, p. 381; Creus, Carlos. Derecho Peñal, tomo 1, Astrea, Buenos Aires, 1998, p. 510.

${ }^{33}$ Creus, Carlos. Op. cit., p. 511; Fontán Balestra, Carlos. Op. cit., p. 582.
} 
condiciones necesarias para producir sus efectos jurídicos. La nulidad (arquetipo de las sanciones civiles) o la anulabilidad del acto jurídico de las partes no enervan el tipo penal analizado.

Reviste interés dilucidar si la nulidad que afecte exclusivamente la formación del documento (el acto del notario en ese caso), es susceptible de sustraer a esta maniobra dolosa del tipo penal. Diversas son las causales que invalidan los actos del autorizante de un instrumento público previstas por la legislación sustancial: la falta de competencia material y territorial por parte del autorizante; la destitución, suspensión o reemplazo del oficial público; actuación de aquel en asuntos en los cuales sus parientes se encuentren interesados; incumplimiento de formalidades legales; falta de firma de las partes; redargución de falsedad del documento (artículos 980, 981, 983, 985, 986, 988, 989 del Código Civil; hoy 290, 291, 294 -defectos de forma- del Código Civil y Comercial de la Nación).

En lo que refiere a las escrituras públicas, el Código Civil establecía otras causales invalidantes: su redacción en soporte papel diverso al protocolo (artículo 998), incumplimiento de recaudos relativos al idioma y ante la intervención de sordomudos (artículos 999 y 1000); faltas relativas a la data, lugar de otorgamiento, firmas e inobservancia del orden cronológico (artículos 1004 y 1005 del Código Civil). El Código Civil y Comercial de la Nación vigente resume en un artículo las causales que conllevan la sanción de nulidad de las escrituras públicas: omisión de la data y lugar de otorgamiento, el nombre de los otorgantes, la firma del escribano y de las partes, la firma a ruego y testigos, en su caso (artículo 309).

Esta norma debe interpretarse sistemáticamente con las que tratan sobre la ineficacia de los instrumentos públicos ya citadas, en atención de que los documentos notariales integran esa categoría (artículo 289). La donación de inmueble requiere, para su validez, el cumplimiento de una forma impuesta legalmente: su celebración en escritura pública (artículo 1810, inciso 1 del Código Civil; artículo 1552 del actual Código Civil y Comercial de la Nación), sin que sea aplicable la subsanación acudiendo a la conversión prevista en los artículos 987 y 1185 del derogado Código Civil, instituto ahora previsto por los artículos 384 y 969 del Código Civil y Comercial de la Nación.

La expresión final del artículo 174, inciso 2, del Código Penal ("aunque el acto sea civilmente nulo”) veda, en principio, posibles distinciones. La invalidez de los actos privados puede alcanzar tanto al realizado por las partes como al relativo a la formación de los documentos portantes, ya sean públicos o privados. ${ }^{34}$ Por lo tanto, resulta indiferente que la patología agreda el

\footnotetext{
${ }^{34}$ Las distintas situaciones que provocan la invalidez (nulidad, anulabilidad) de los actos juridicos se encuentran
} 
acto de las partes o el que corresponde al autorizante (las llamadas nulidades instrumentales). La signatura de la víctima en el documento y la comprobación de los restantes elementos descriptivos del tipo penal determinan la existencia del delito. En cambio, resultan totalmente ajenos al tipo legal los denominados actos jurídicos inexistentes. Es el caso de la escritura redactada en el protocolo pero que carece de firmas. ${ }^{35}$

\subsection{La valoración del tribunal}

El Tribunal califica a la escritura de donación como nula atento "el palmario vicio en el consentimiento que conlleva haber sido suscripta por quien se encontraba afectada por una significativa disminución de su capacidad neurocognitiva”. Cita en apoyo de su afirmación los artículos 141, 152 bis, inciso 2, 1042, 954 del Código Civil y menciona calificada doctrina civilista.

De ello se infiere que los padecimientos de la víctima al tiempo de la celebración del negocio invalidado enervaron los elementos internos de su voluntad, esto es, el discernimiento, la intención y la libertad, cualidades requeridas conjuntamente para que el acto sea reputado voluntario y generador de obligaciones. ${ }^{36} \mathrm{La}$ ancianidad de la víctima, sumada a su salud físicomental quebrantada, resultaron determinantes para menoscabar su autonomía y aptitudes para comprender adecuadamente las consecuencias del acto otorgado. De allí que el acto jurídico deviene involuntario y su otorgamiento no desencadena consecuencia alguna para el autor que se encuentre en las condiciones de vulnerabilidad apuntadas.

Se advierte, de acuerdo con lo expresado en la sentencia, que la "cuidadora" o "guardadora de hecho" ejercía una influencia determinante sobre las decisiones de la persona otorgante del acto invalidado, valiéndose de la intimidación y malos tratos (artículos 937, 1045 del Código Civil). ${ }^{37}$

reguladas dentro del contexto del Código Civil ya con rango de principios generales (artículos 18, 1037, 1038, 1039, 1040, entre otros) y contemplan situaciones especificas (caso de las llamadas "nulidades instrumentales").

${ }^{35} \mathrm{~A}$ diferencia de los actos nulos o anulables, en los actos jurídicos inexistentes se comprueba la carencia de elementos necesarios para su formación. Su elucubración se debe a la doctrina francesa, la cual ha encontrado recepción en autores nacionales y extranjeros.

${ }^{36}$ Artículo 900 del Código Civil. Resulta ilustrativo el primer párrafo de la nota a ese precepto: "El elemento fundamental de todo acto es la voluntad del que lo ejecuta". Para LLambias, "el autor de un hecho involuntario carece de responsabilidad, no siendo entonces viable imputarle ninguna de las consecuencias de su actividad". LLAmbias, Jorge Joaquin. Tratado de Derecho Civil, tomo 2, Lexis Nexis, Buenos Aires, p. 259.

${ }^{37}$ Designamos como "guardadores de hecho" a los sujetos que cumplen en forma transitoria o permanente tareas de asistencia a personas que padecen limitaciones físico-mentales. Por lo general, su función se limita a la atención de necesidades básicas (mandados, pequeñas tareas de mantenimiento, ayuda en tareas domésticas), pero pueden involucrarse en gestiones de mayor trascendencia: internaciones, primeros auxilios, cuidados permanentes, actos de administración, etcétera. Esa función carece de regulación legal en nuestro pais. La figura afin parece encontrarse en el mandato tácito 


\section{El notario y el discernimiento de los otorgantes. La función preventiva del asesoramiento}

Todo documento notarial contiene un juicio por parte del autorizante relativo al discernimiento de los comparecientes en el momento de la realización del acto, aunque el texto no lo indique expresamente. ${ }^{38}$ Bien entendido es que cualquier mención que eventualmente se consigne, relacionada con la capacidad de las partes, no goza del amparo de la fe pública, porque integra la categoría de "juicios" que emite el notario. ${ }^{39}$

Como es sabido, la fe pública es la veracidad impuesta por el ordenamiento legal a las afirmaciones del oficial público consignadas en el documento de su autoría -escritura pública, acta protocolar o actuaciones extra-protocolaresque refiere a los actos o hechos cumplidos por él mismo o aquellos ocurridos en su presencia. ${ }^{40}$ Esa creencia de carácter forzoso se limita a lo que el escribano afırma haber realizado por sí mismo (traslado a un determinado lugar, por ejemplo), a los hechos y situaciones percibidos sensorialmente por él (manifestaciones y actos realizados por las partes, descripciones de cosas y de acontecimientos ocurridos en su presencia), incluyéndose la fecha y autoría del instrumento. Cabe recordar, en apretada síntesis, que los efectos de la fe pública alcanzan tanto a las partes otorgantes como a los terceros. ${ }^{41}$

A diferencia de lo establecido para el notariado español, nuestro derecho positivo no obliga a los escribanos que consignen en los documentos que

(artículos 1873 y 1874, del Código Civil), en la representación aparente y el mandato sin representación, figuras previstas en los artículos 367 y 1321 del actual Código Civil y Comercial de la Nación. Esta interesantísima figura ha sido tratada por la doctrina española. Puede consultarse: Frábega Ruiz, Cristóbal Francisco. "La guarda de hecho y la protección de las personas con discapacidad", Universitarias Ramón, Madrid.

${ }^{38}$ Resulta frecuente leer, en escrituras fechadas varias décadas atrás, la expresión "personas hábiles y de mi conocimiento", consignada con posterioridad a los datos de los otorgantes. Esa afirmación suele constar actualmente en las escrituras de testamento por acto público, donde con mayor claridad se indica respecto al testador un párrafo que puede ser de este tenor: "encontrándose a mi juicio en su perfecta razón" y sirve como elemento probatorio que apoya la presunción de capacidad del otorgante establecida por el artículo 3616 del cc. Trigo Represas sostiene que "el juicio de capacidad integra el contenido intelectual y hace a la autenticidad interna del instrumento por ser presupuesto de su validez". Agrega que la autorización del documento por el notario "hace presumir que él mismo evaluó los elementos constitutivos de la capacidad de los sujetos intervinientes". TRIGo Represas, FétIX. "Responsabilidad civil de los escribanos de registro", en Revista Notarial, No. 845, pp. 1270-1271. ${ }^{39}$ Notas del codificador a los artículos 993 y 3616 del Código Civil. Zinny, MARIo Antonio. El acto notarial (dación de fe), Depalma, Buenos Aires, 1990, p. 36. Pérez Gallardo refiere que algunos autores prefieren la expresión calificación notarial. Distingue esa afirmación de la dación de fe, reproduciendo un párrafo de Giménez Arnau: "un acto o juicio personal que no pertenece al juxta verum dictum de la fe pública, sino más bien, al principio de legalidad; juxta legem actum". Pérez Gallardo, Leonardo. "Diez Interrogantes sobre el Juicio Notarial de Capacidad: Un Intento de Posibles Respuestas", en Revista del Instituto de Derecho e Integración, No. 9, año 5, 2013, pp. 38-39.

${ }^{40}$ Artículo 993 y concordantes del Código Civil; Cuture, Eduardo. "El Concepto de Fe Pública" en Lecturas Esenciales de Derecho Notarial. Gaceta Notarial, Cuzco, Perú, p. 39.

${ }^{41}$ Zinny, Mario Antonio. Op. cit., p. 69. Artículos 993, 994, 996 del Código Civil. 
extienden su juicio sobre la aptitud discerniente de los otorgantes del acto. Esa apreciación integra el conjunto de los deberes que les caben como operarios del derecho o intérpretes jurídicos. ${ }^{42}$ Se trata de tareas vinculadas con la dación fe, pero que se cumplen con la etapa previa a la formación de los actos jurídicos representados por el documento notarial y que devienen indispensables a los fines de garantizar la eficacia y validez de las actuaciones. Los romanos designaron a esas actividades como respondere; son comunes al defensor (abogado) y al escribano, en tanto incumben a ambos en su calidad de intérpretes jurídicos. ${ }^{43}$ Entre nosotros se rotula como asesoramiento y es uno de los deberes impuestos al notario, contemplados específicamente en las leyes orgánicas notariales. ${ }^{44}$

El asesoramiento se concreta a través de las audiencias que mantiene el notario con los requirentes en forma previa a la instrumentación del negocio jurídico o diligencia requeridos. Esas entrevistas permiten al profesional ilustrar a los interesados sobre los aspectos jurídicos de la actuación pretendida y, al mismo tiempo, efectuar la apreciación del nivel de entendimiento de aquellos. De allí que esos contactos personales resulten indispensables a los fines de la individualización de las partes, la prestación del asesoramiento (ya sea en forma oral o escrita) y la detección de eventuales irregularidades. Tales procedimientos permiten llevar a la práctica las acciones tendientes a neutralizar todo posible litigio, ya que una vez advertida la patología jurídica se adoptan las medidas tendientes a su subsanación, particularmente las de carácter preventivo. ${ }^{45}$

La valoración del estado de lucidez de los otorgantes del acto notarial integra ese conjunto de acciones preventivas, con la particularidad de que principia en la primera audiencia y solamente concluye una vez autorizado el documento.

${ }^{42}$ El "Reglamento de la Organización y Régimen del Notariado" de España establece en su artículo 167: "El notario, en vista de la naturaleza del acto o contrato y de las prescripciones del derecho sustantivo en orden a la capacidad de las personas, hará constar, que a su juicio, los otorgantes, en el concepto con que intervienen, tienen capacidad civil suficiente para otorgar el acto o contrato de que se trate" (Decreto del 2 de junio de 1944, reproducido por la Junta de Decanos de los Colegios Notariales de España, Madrid, 1971, p. 130). Concordantemente, el artículo 156 de ese precepto legal ordena: "La comparecencia de toda escritura indicará: [...] 8 La afirmación, a juicio del Notario, y no apoyada en el solo dicho de los otorgantes, de que éstos tienen la capacidad legal o civil necesaria para otorgar el acto o contrato a que la escritura se refiera". Recuerda Pérez Gallardo que "la apreciación de la capacidad del otorgante -según expresa Rodríguez Adrados-, fue considerada históricamente ajena a la función notarial, ello a partir de la concepción puramente sensorial tenida sobre ésta". Op. cit., p. 39.

${ }^{43}$ Carneluti, Francesco. "La Figura Juridica del Notario", en Gaceta Notarial, Cuzco, Perú, 2011, p. 149; Martinez Segovia, Francisco. Función notarial, Ediciones Jurídicas Europa América, 1961, p. 22.

${ }^{44}$ La legislación notarial de la Provincia de Mendoza (ley 3058/64, texto ordenado en 2005), prevé en su artículo 2 como actividad notarial "el asesoramiento jurídico notarial en general y la formulación, en su caso, de dictámenes orales o escritos".

${ }^{45}$ Carnelutti destaca la acción preventiva del notario al afirmar: "cuanto más consejo del notario, cuanta más conciencia del notario, cuanta más cultura del notario, menos posibilidad de litis". Carnelumi, Francesco. Op. cit., p. 147. 
Si el fedatario, como resultado de sus comprobaciones, arribara a la convicción fundada de que algún otorgante carece de discernimiento, intención y libertad, requeridos para la formación de los actos jurídicos (artículo 900 del Código Civil), deberá negarse a prestar su ministerio.

La doctrina notarial española, coincidentemente, puntualiza que el notario debe negarse a prestar su autorización al acto requerido "cuando a su juicio, todos o algunos de los otorgantes carezcan de la capacidad legal necesaria para el otorgamiento del acto que pretendan”. ${ }^{46}$ La Ley Orgánica del Notariado Bonaerense (número 9020/1978 y modificatoria número 12623) contempla, en su artículo 131, inciso 3, entre las causas que permiten al escribano rehusar la prestación de su ministerio: "Dudas razonables respecto del estado mental del requirente o de su libertad de volición”. Similares ordenamientos vigentes en otras demarcaciones imponen al fedatario la obligación de "intervenir profesionalmente en los casos que sea requerido, no siendo esa intervención contraria a las leyes". ${ }^{47}$

La instrumentación de actos a título gratuito amerita un examen particularmente cuidadoso por parte del profesional respecto al estado de discernimiento, intención y libertad del transmitente de los bienes. Nótese la protección especial que el legislador otorga al donante a fin de evitar una posible situación de indigencia, invalidando la donación de todos sus bienes presentes en caso de que no se prevea la reserva de usufructo o una porción suficiente para subvenir a sus necesidades (artículo 1800).

El brazo de la tutela legal limita igualmente las atribuciones de los mandatarios de los donantes: el instrumento que faculta la realización de tales actos en nombre de otro debe especificar los bienes objeto de la donación (artículo 1807, inciso 6). Ante esos supuestos (liberalidades), resulta aconsejable que el notario profundice sus contactos con el disponente de los bienes a fin de dilucidar con acierto el grado de comprensión y de autonomía de éste.

Sin embargo, como el notario no emite una opinión de carácter técnico, sino -insistimos- un juicio sobre la capacidad de las partes (implícito en el documento autorizado), su responsabilidad se generaría en el caso de que su actuación fuere dolosa o si mediara grave negligencia. ${ }^{48}$ Así parece haberlo entendido el Tribunal en el caso examinado en el punto anterior.

\footnotetext{
${ }^{46}$ Simo Santoja, VICEnte. "El notariado y los derechos fundamentales", Ponencias del Notariado Español, XXII Congreso Internacional del Notariado Latino, Buenos Aires, 1998, p. 252.

${ }^{47}$ Reproducimos parcialmente el artículo 11, inciso d, de la Ley Orgánica del Notariado Santafesino número 6898 y modificatorias. Similares expresiones se encuentran en otros similares, tales como la Ley 404 de la Ciudad Autónoma de Buenos Aires (artículo 29) y la recordada ley 3058 de la Provincia de Mendoza (artículo 9).

${ }^{48}$ LLoRENS, LUIS. El Notario ante deficientes mentales. Hacia una revitalización de la capacidad en el derecho civil, p. 142.
} 
Debe recordarse que el fedatario debe ajustar su actuación a un postulado admitido universalmente en el mundo jurídico: "la capacidad de obrar constituye una presunción iuris tantum". ${ }^{49}$ En consecuencia, toda negativa a la prestación de su ministerio que se apoye en motivos fútiles genera responsabilidad en cabeza del fedatario renuente (artículos 1074 y concordantes del Código Civil; artículo 1724, 1725 y concordantes del actual Código Civil y Comercial de la Nación, normas que tratan sobre la responsabilidad derivada de conductas omisivas del agente que causen perjuicio). Su estatus de profesional del derecho en ejercicio de una función pública conlleva el deber de prestación del ministerio para el cual fue designado, como regla general.

En cuanto a la registración de las sentencias a las limitaciones de la capacidad y a la nulidad otorgados por las personas afectadas con posterioridad a esa toma de razón (artículos 39 y 44 del Código Civil y Comercial de la Nación), a la fecha no se encuentra operativo un procedimiento que garantice el conocimiento de esa situación por parte del autorizante. Ello sin contar con la dificultad de su aplicabilidad en circunstancias de que el nacimiento los otorgantes haya ocurrido en demarcaciones diversas a las del lugar de celebración del acto jurídico o en el extranjero. Le resta al escribano aceptar la declaración de las partes de que no se encuentran en la situación que se comenta.

\section{La tutela de los derechos de las personas en situación de vulnerabilidad}

A modo de actualización de esta monografía, se indican algunos preceptos incluidos en el Código Civil y Comercial de la Nación, sancionado por Ley 26694, en vigencia desde el 1 de agosto de 2015. Responden a la finalidad tuitiva de los derechos de las personas en situación de mayor vulnerabilidad, y a la realización concreta del principio de igualdad ante la ley e igualdad real de oportunidades (artículos 14 y 75, inciso 23 de la Constitución Nacional).

Corolario de lo establecido por el artículo 75, inciso 17, de la Carta Magna (reconocimiento de la preexistencia étnica y cultural de los pueblos indígenas argentinos) es el derecho a la posesión y propiedad comunitaria por parte de las comunidades indígenas "de las tierras que tradicionalmente ocupan y de aquellas aptas y suficientes para el desarrollo humano”, reglado en el artículo 18. La función social del derecho de dominio contemplado por esa normativa le confiere, como características distintivas, inalienabilidad, inembargabilidad

\footnotetext{
${ }^{49}$ LANDESTOY MÉndeZ, PEDRo LuIs. "La discapacidad intelectual y la testimentafio activa: una visión desde la convención de los derechos de la personas con discapacidad", en Revista del Instituto de Derecho e Integración, No. 6, año 3, p. 132.
} 
e inejecutabilidad; tampoco puede ser objeto de la constitución de garantías reales o embargos, salvo en garantía del pago de créditos otorgados por entidades oficiales para la concreción de planes de desarrollo de esas comunidades. Esa interpretación resulta de armonizar lo establecido por el artículo 18, la Constitución Nacional y la ley 23302 y decreto 155/89.50

En materia de capacidad de derecho, rige con carácter excepcional su privación o limitación respecto "de hechos, simples actos o actos jurídicos determinados” (segundo párrafo, artículo 22). De allí resulta que toda limitación a la capacidad y al libre ejercicio de la voluntad deben estar previstas legalmente, no siendo posible su aplicación por vía analógica. El principio expuesto sintéticamente se funda en principios constitucionales (artículo 19), de derecho privado sustancial (artículos 53 y 62 del Código Civil) y jurisprudencia de la Corte Suprema de Justicia de la Nación. Ontológicamente, refiere al expreso reconocimiento al derecho de la personalidad jurídica de cada individuo, preexistente a toda concesión del poder público estatal. ${ }^{51}$

Las limitaciones a la capacidad del ejercicio de los derechos de la persona humana pueden estar previstas en el mismo Código y en una sentencia judicial (artículo 23). La admisión de las restricciones al ejercicio de los derechos de las personas también resulta de lo previsto por otras leyes especiales y requieren de la fundamentación legal en toda sentencia que las imponga (la omisión de este último requisito podría tipificar delito de prevaricato), prevaleciendo la regla general de la capacidad. ${ }^{52}$

La interpretación del artículo 24 que refiere a las personas consideradas "incapaces de ejercicio" (persona por nacer, que no cuenta con la edad y grado de madurez suficiente y la declarada incapaz en la extensión dispuesta por la sentencia) debe resultar armónica con los postulados sobre la Convención de los Derechos del Niño, incorporados por ley nacional 26061. Estos postulados marginan el viejo principio del Código Civil que otorgaba prevalencia al concepto de incapacidad general de los menores, reemplazándolo por aquel que les garantiza el derecho de expresar sus opiniones en asuntos que les conciernen de acuerdo con su edad y grado de madurez.

El criterio se complementa con lo estatuido por el artículo 26, que restringe la aplicación de la regla general relativa a la representación de los menores de edad a las situaciones en que deba suplirse su falta de capacidad de ejercicio.

\footnotetext{
${ }^{50}$ Código Civil y Comercial Comentado, Anotado y Concordado. Eduardo Gabriel Clusellas (Coord.), tomo 1, artículos 1 a 331, Astrea - fen - Editora Notarial, Buenos Aires, abril de 2015, p. 66.

${ }^{51}$ Véase el comentario al artículo 22 en la obra citada precedentemente (página 86 y siguientes).

${ }^{52}$ RaIMIL, Alicia BeAtriz y Llorens, Luis Rogelio. Apuntes para la práctica notarial acerca del régimen de capacidad de las personas y de los derechos personalisimos en el Código Civil y Comercial (Ley 26994), pp. 5 y 6.
} 
Esto se advierte en las diversas excepciones previstas al principio general que en su primer párrafo indica: "La persona menor de edad ejerce sus derechos a través de sus representantes legales”.

Los párrafos siguientes autorizan que ejerza por sí mismo los actos permitidos por el ordenamiento jurídico si "cuenta con edad y grado de madurez suficiente", el derecho "a ser oída en todo proceso judicial que le concierne", la presunción relativa a la aptitud para decidir por sí respecto de ciertos tratamientos no invasivos, la necesaria prestación del consentimiento con asistencia de sus progenitores a los fines de tratamientos invasivos y su consideración como adulto a partir de los 16 años en "decisiones atinentes a su propio cuerpo". ${ }^{53}$

El criterio restrictivo a la limitación de la capacidad jurídica de las personas y tutelar ante situaciones de vulnerabilidad se advierte en el artículo 31, que reconoce la presunción del ejercicio de su capacidad, aún respecto de aquellas internadas en establecimientos asistenciales (inciso $a$ ) y establece el carácter excepcional de las limitaciones que "se imponen siempre en beneficio de la persona" (inciso $b$ ).

El sistema de apoyo, alternativa diversa a la representación que presupone la sustitución de la voluntad, se regula en los artículos 32 (persona con capacidad restringida o incapacidad), 38 (sobre el alcance de la sentencia restrictiva de las funciones y actos de la persona) y el 43 (concepto y función del apoyo). Se trata de funciones de asistencia que acompañan la voluntad de la persona y se adoptan en función del grado de restricción de la capacidad de obrar establecido en la sentencia.

La protección a la intimidad personal o familiar, la honra, la reputación, imagen, identidad o a cualquier menoscabo de la dignidad personal (artículo 52), se garantizan mediante el ejercicio de las acciones aplicables a la prevención del daño y su reparación (artículo 1708 y siguientes). La protección del derecho a la imagen (artículo 53) es un corolario de aquel principio rector.

Incluimos en esta escueta reseña la glosa relativa a la norma que consagra la inexigibilidad del cumplimiento del " contrato que tiene por objeto la realización de actos peligrosos para la vida o integridad de las personas” (artículo 54). Entre esas prácticas deleznables, recordamos las tristemente conocidas "picadas" automovilísticas, cuyo riesgo se extiende a los terceros cuando se concretan en lugares inadecuados y sin que se adopten medidas preventivas.

Las expresas limitaciones a la disposición de derechos personalísimos (artículo 55) a los actos de disposición sobre el propio cuerpo (artículo 56), que

53 "Cabe afirmar entonces que la representación legal, no es la regla general, sino el medio válido para subsanar la falta de capacidad de ejercicio del niño, niña y adolescente cuando fuere necesario." RAJMLL, ALIII, LLoRens, LUIS Rogelio. Op. cit., p. 16. 
junto con las directivas médicas anticipadas (artículo 60) debieran prever en forma obligatoria su instrumentación en escritura pública, integran la amplia gama de normas tutelares de las personas en situación de vulnerabilidad. ${ }^{54}$

\section{Conclusiones}

Todo ser humano es esencialmente vulnerable debido a su finitud y habida cuenta de que, en gran medida, su supervivencia (especialmente durante la infancia, enfermedad y vejez) depende de los cuidados de otros. Esa condición "innata" de vulnerabilidad admite numerosos matices que, respondiendo a una infınita variedad de situaciones (pertenencia a determinados grupos sociales o políticos, raza, hábitat), pueden profundizarla o morigerarla hasta reducirla a una mínima expresión.

Las desigualdades de hecho existentes entre los seres humanos agravan el estado de vulnerabilidad de numerosas personas. Esa situación se verifica palmariamente en los sujetos afectados por minusvalías mentales.

Tradicionalmente, las personas dotadas de capacidades mentales diferentes recibieron por parte de la sociedad un tratamiento favorable a su exclusión. Con acierto, los ha caracterizado como "escondidos de la sociedad". Bajo el falaz argumento del mejoramiento de la raza humana, se llegó al extremo de promover y llevar adelante su eliminación (momentos aberrantes en la historia de la humanidad).

El común denominador aplicó políticas proclives a la discriminación de estos sujetos y las legitimó a través de un aceitado régimen normativo que, autoproclamándose tuitivo y fundándose en principios de seguridad jurídica, colocaba a tales personas (designadas colectivamente como incapaces, incluyendo dentro esa categoría a los menores) en situación de objetos, ignorando absolutamente su voluntad.

Nuestro Código Civil receptó ampliamente los principios resumidos en el punto anterior. Un antecedente normativo que atemperó el rígido sistema vigente fue la modificación operada mediante la introducción del artículo 152 bis (en los casos contemplados por esa norma, el curador se limita a cumplir funciones de asistencia, ya no suple la voluntad del pupilo).

El largo camino hacia el efectivo ejercicio de los derechos y protección normativa de las personas más vulnerables reconoce un punto de partida en los principios del llamado constitucionalismo social que en nuestra Carta Magna se refleja en el texto de su artículo 14 bis (reforma de 1956). Esa reforma

\footnotetext{
${ }^{54}$ Entendemos que en lo que hace a la forma del otorgamiento de directivas anticipadas en materia de salud, rige lo dispuesto por la ley 26529, con la modificación realizada al artículo 11 por la ley 26742, que impone la forma escrita de "la declaración de voluntad ante escribano público o juzgados de primera instancia, para lo cual se requerirá la presencia de dos testigos".
} 
complementa y trasciende al principio de igualdad formal ante la ley, consagrado en la Constitución originaria (artículos 14 y 16), respuesta ineficaz ante las abismales desigualdades económico-sociales. La igualdad de oportunidades alcanza reconocimiento constitucional en la reforma operada en 1994 (artículo 75, inciso 23).

Un conjunto normativo sancionado con posterioridad a la Segunda Guerra Mundial consistente en tratados dotados de jerarquía superior a las leyes (artículo 22 de la Constitución) y legislación específica, se erige en garante del efectivo ejercicio de los derechos de las personas en situación de mayor vulnerabilidad. Se trata del claro reconocimiento a los derechos humanos, concebidos en su mayor amplitud.

De la normativa analizada pueden extractarse, atendiendo a su relevancia, el reconocimiento de principios relativos a la igualdad (entendida desde punto de vista integral), el respeto al derecho de autodeterminación y a la dignidad de las personas en situación de mayor vulnerabilidad, el rechazo a toda forma de discriminación en su sentido negativo y la tutela efectiva de tales derechos a través de regímenes sancionatorios (civiles y penales).

Corresponde al notario, profesional del derecho en ejercicio de una función pública y como tal garante de los derechos de las personas, adoptar las medidas preventivas que aseguren la plena validez de los actos jurídicos realizados con su intervención. Entre los numerosos resguardos, adquiere un papel preponderante el juicio que emite el fedatario relativo al grado de discernimiento de los otorgantes, que principia en la etapa correspondiente a las audiencias preliminares y concluye una vez autorizado el documento. La inmediación entre el notario y las partes permite al profesional ponderar el grado de comprensión de cada sujeto.

Como principio general, el escribano debe cumplir con la regla que consagra la prestación obligatoria de su ministerio. En lo que refiere a la aptitud de los otorgantes, deberá atender al principio de presunción de capacidad.

Atento a que hasta la fecha no se encuentra operativo el registro de las sentencias restrictivas a la realización de determinados actos jurídicos y atendiendo las dificultades de su implementación (artículo 39 del Código Civil y Comercial de la Nación), el notario podrá requerir de las partes la declaración con carácter jurado de que no se encuentran en esa situación. La manifestación integrará el texto del documento notarial que se autorice y se sumará al espectro de medidas que adopta el fedatario, tendientes a resguardar la integridad de los actos representados.

El Código Civil y Comercial de la Nación, sancionado por ley 26994, contiene una amplia gama de medidas tutelares para personas en situación de mayor vulnerabilidad. Respondiendo a tratados internacionales de jerarquía constitucional, privilegia la autonomía de la voluntad de esas personas, armonizándola con los principios protectores. 